\title{
Nascent osteoblast matrix inhibits osteogenesis of human mesenchymal stem cells in vitro
}

Catherine M. Kolf ${ }^{1,2,4}$, Lin Song ${ }^{1,5}$, Jeannine Helm ${ }^{1,6}$ and Rocky S. Tuan ${ }^{1,3^{*}}$

\begin{abstract}
Introduction: Adult mesenchymal stem cells (MSCs) are considered promising candidates for cell-based therapies. Their potential utility derives primarily from their immunomodulatory activity, multi-lineage differentiation potential, and likely progenitor cell function in wound healing and repair of connective tissues. However, in vitro, MSCs often senesce and spontaneously differentiate into osteoblasts after prolonged expansion, likely because of lack of regulatory microenvironmental signals. In vivo, osteoblasts that line the endosteal bone marrow surface are in close proximity to MSCs in the marrow stroma and thus may help to regulate MSC fate.

Methods: We examined here how osteogenic differentiation of MSCs in vitro is affected by exposure to osteoblastic cells (OBCs). Human bone marrow MSCs were exposed to OBCs, derived by induced osteogenic differentiation of MSCs, either directly in contact co-cultures, or indirectly to OBC-conditioned medium or decellularized OBC extracellular matrix (ECM).

Results: Our results showed that OBCs can act as negative regulators of MSC osteogenesis. mRNA expression profiling revealed that OBCs did not affect MSC osteogenesis in direct contact cultures or via secreted factors. However, seeding MSCs on decellularized OBC ECM significantly decreased expression of several osteogenic genes and maintained their fibroblastic morphologies. Proteomic analysis identified some of the candidate protein regulators of MSC osteogenesis.

Conclusions: These findings provide the basis for future studies to elucidate the signaling mechanisms responsible for osteoblast matrix-mediated regulation of MSC osteogenesis and to better manipulate MSC fate in vitro to minimize their spontaneous differentiation.
\end{abstract}

Keywords: Mesenchymal stem cells, Osteoblasts, Extracellular matrix, Osteogenesis, Stem cell niche

\section{Introduction}

Mesenchymal stem cells (MSCs) are multipotent cells resident in adult tissues that function in wound healing and repair of connective tissues, especially the musculoskeletal system. Capable of extensive expansion in vitro [1], they are an exciting cell type to study because of their therapeutic potential in tissue engineering and

\footnotetext{
*Correspondence: rst13@pitt.edu

'Department of Health and Human Services, Cartilage Biology and Orthopaedics Branch, National Institute of Arthritis and Musculoskeletal and Skin Diseases, National Institutes of Health, Bethesda, MD, USA

${ }^{3}$ Department of Orthopaedic Surgery, Center for Cellular and Molecular Engineering, University of Pittsburgh School of Medicine, 450 Technology Drive, Room 221, Pittsburgh, PA 15219, USA

Full list of author information is available at the end of the article
}

regenerative medicine [2]. MSCs are commonly differentiated into osteoblasts, chondrocytes and adipocytes [3], as well as other cell types $[4,5]$. Still more promising, MSCs have been shown to have immunomodulatory properties, allowing them to evade the immune system when transplanted [6].

A practical hurdle in the application of MSCs is their tendency to undergo spontaneous differentiation upon extended propagation in vitro. Specifically, osteogenesis appears to be the default differentiation pathway for long term cultures of MSCs [7], causing them to senesce and lose their therapeutic potential. However, in vivo, both of these processes are prevented due to the specialized niche in which MSCs reside. Recapitulation of this niche 
in vitro would permit more extensive expansion of MSCs without the loss of their multi-lineage differentiation potential. The feasibility of such an endeavor requires understanding the nature of the MSC niche.

In the bone marrow, the MSC niche is, at least partially, perivascular [8]. However, MSCs are likely in contact with both endothelial cells and osteoblasts (OBs), which line the bone marrow cavity. Since OBs have been implicated in the hematopoietic stem cell niche $[9,10]$, it seems likely that they could also be key players in the MSC niche. A number of studies have assessed the effects of OBs and their secreted soluble and extracellular matrix (ECM) proteins on MSC osteogenesis [11-15]. For example, co-culturing of embryonic mouse MSCs and OBs, separated in a Transwell set-up, showed that factors secreted by OBs can cause a 30-fold increase in MSC proliferation and a decrease in their alkaline phosphatase (ALP) activity, indicative of less osteogenic differentiation [11]. While the active factors responsible for this observed effect have not been ascertained, both bone morphogenetic proteins (BMPs) and insulin-like growth factors (IGFs) are secreted by OBs and have been implicated in several niche functions in other systems, including stem cell maintenance [16-18] and asymmetric cell division [19].

On the other hand, both BMPs and IGFs can also be found sequestered in the ECM of OBs; in fact, BMPs were first identified in demineralized bone matrix (DBM) because of their activity in inducing bone formation [20]. While several ECM molecules, in their purified forms, have been shown to enhance bone formation (e.g., collagen type I [21]), the reactivity of MSCs to native $\mathrm{OB}$ matrix, with its three-dimensionality and protein-protein interactions, is likely to be more complex. In addition, it is important to examine the interactions between human MSCs and nascent human OBs, the most likely osteoblastic cell type to interact with MSCs in the native bone marrow environment. Mature bone cells, such as fully differentiated OBs and osteocytes, from which DBM is created, are encased in bony matrix and are most likely exposed to MSCs only upon tissue injury, such as bone fracture. This information serves as the foundation for our study of MSC osteogenesis, in which we tested the effects of relatively immature osteoblastic cells (OBCs), derived in vitro from MSCs. Specifically, we have examined the influence of cell-cell interaction, and secreted factors and extracellular matrix produced by the OBCs on MSC osteogenic differentiation.

\section{Materials and methods Cell culture}

Human femoral heads were generously obtained from Dr. Paul Manner (University of Washington, Seattle) from total hip arthroplasty patients with informed consent and
Institutional Review Board approval. Bone marrow MSCs were isolated as described previously [16], plated in expansion medium (EM) (DMEM, 9 \% lot-selected fetal bovine serum (Invitrogen, Grand Island, NY; MSCqualified), $1 \%$ penicillin/streptomycin/Fungizone) in $150-\mathrm{cm}^{2}$ culture flasks (Corning or Nunc), and incubated at $37{ }^{\circ} \mathrm{C}, 5 \% \mathrm{CO}_{2}$. One to two days later, hematopoietic cells were rinsed away with phosphatebuffered saline (PBS) or Hank's Balanced Salt Solution (HBSS). MSCs were routinely passaged every three to four days before reaching confluency.

To obtain OBCs, second or third passage MSCs were trypsinized and re-plated in osteogenic medium (OM) consisting of EM plus $10 \mathrm{mM} \beta$-glycerophosphate, 19.5 $\mathrm{mM}$ L-ascorbic acid-2-phosphate, $10 \mathrm{nM}$ dexamethasone (all from Sigma-Aldrich, St. Louis, MO, USA), 10 nM 1,25-dihydroxyvitamin $\mathrm{D}_{3}$ (Enzo, Farmingdale, NY, USA) [16]. MSCs were cultured in OM for a minimum of 14 days before being considered OBCs.

\section{Direct co-cultures of MSCs and OBCs}

To assess endogenous levels of osteoblastic mRNAs in osteogenically differentiating MSCs in contact with OBCs, MSCs and OBCs were co-cultured in a 1:4 ratio at 9,000-10,000 cells $/ \mathrm{cm}^{2}$. Before co-culture, trypsinized MSCs were stained with the cell tracker CM-DiI (Thermo Fisher, Waltham, MA; $10^{6}$ cells $/ \mathrm{mL}+8 \mu \mathrm{L}$ CMDiI, $37^{\circ} \mathrm{C}$, for five min, then $4{ }^{\circ} \mathrm{C}$, for $15 \mathrm{~min}$ ) to distinguish them from $\mathrm{OBCs}$ and to allow subsequent fluorescence-activated cell sorting (FACS). Three coculture combinations were tested in both EM and OM: (1) DiI-labeled MSCs mixed with unlabeled OBCs, (2) DiI-labeled MSCs mixed with unlabeled MSCs, and (3) unlabeled, MSC-only cell populations, with the latter two conditions serving as controls. Samples were harvested pre-culture, and at culture days 6 and 12. MSC-only cultures were trypsinized, centrifuged, resuspended in $1 \mathrm{~mL}$ Trizol (Invitrogen), and stored at $-80{ }^{\circ} \mathrm{C}$; mixed cultures were trypsinized and frozen in dimethyl sulfoxide (DMSO) freeze medium (BioVeris Corporation, Gaithersburg, MD, USA) until the time course was complete. The DiI-positive cells were fractionated using a BectonDickinson three-laser Dako MoFlo FACS sorter, pelleted by centrifugation, resuspended in $1 \mathrm{~mL}$ Trizol, and stored at $-80{ }^{\circ} \mathrm{C}$. Osteogenesis was assessed by conventional real time RT-PCR and by PCR array analysis (SuperArray, Qiagen, Valencia, CA, USA; see below).

\section{Conditioned medium cultures}

To assess the effects of OB-secreted factors on MSC osteogenesis, EM and OM were conditioned for three days by OBCs that had completed 11-14 days of osteogenesis. Conditioned medium $(\mathrm{CM})$ was frozen at $-80{ }^{\circ} \mathrm{C}$ until use. $\mathrm{OM}$ incubated without cells for three days, 
referred to as aged osteogenic medium (AOM), served as the control. Thawed CM was mixed 1:1 with fresh OM before use (Note: Fresh OM was added to minimize possible medium nutrient deprivation as a confounding factor). MSCs, seeded at $8-10 \times 10^{3} / \mathrm{cm}^{2}$ in 6 - and 12 well plates and exposed to $\mathrm{CM}$ every three days, were analyzed for osteogenesis, as described below.

\section{Matrix cultures}

The effects of devitalized/decellularized OBC ECM on MSC osteogenesis were analyzed as follows: MSCs seeded at a density of $8-10 \times 10^{3}$ cells $/ \mathrm{cm}^{2}$ in 6-well plates were cultured in $\mathrm{OM}$ for at least 14 days, rinsed with HBSS, and decellularized by lysis, either with three washes of $3 \mathrm{~mL} /$ well MilliQ-purified water $\left(\mathrm{ddH}_{2} \mathrm{O}\right)$ or by one wash of $1 \mathrm{~mL} /$ well $0.5 \%$ deoxycholate (SigmaAldrich) in $\mathrm{dd}_{2} \mathrm{O}$ (DOC) for $30 \mathrm{~min}$ at $4{ }^{\circ} \mathrm{C}$. The plates were then washed with HBSS three times for at least three min each time. Live/Dead staining (Invitrogen) was performed in one well of each treatment type to ensure $100 \%$ cell death. MSCs were then seeded at 8-10 $\times$ $10^{3}$ cells $/ \mathrm{cm}^{2}$ on top of the two types of matrix, with tissue culture plastic as the control, and osteogenesis was assessed as described below.

MSC proliferation was assessed fluorimetrically (494 $\mathrm{nm} / 567 \mathrm{~nm})$, based on calcein incorporation and $\mathrm{Ca}^{2+}$-dependent fluorescence, after Live/Dead staining (Invitrogen) performed on a Wallac Victor ${ }^{2} \mathrm{~V}$ plate reader (Perkin Elmer, Waltham, MA, USA). Nine measurements were made in a $3 \times 3$ pattern within each well of a 24-well plate, corrected with readings of matrix without cells.

\section{Real-Time RT-PCR}

RNA extracted from frozen Trizol samples was reverse transcribed using oligo-d(T) and a First Strand Synthesis kit (SSII, Invitrogen) and the cDNA was amplified using SybrGreen (BioRad, Hercules, CA, USA) on an iCycler (BioRad). Primer sets $\left(5^{\prime}-3^{\prime}\right)$ were designed (see Additional file 1: Table S1) for the following human genes: osteocalcin (OC), ALP, Runx2, collagen type I, $\alpha 2$ (Col I), and glyceraldehyde 3-phosphate dehydrogenase (GAPDH). Standard curves generated using a 10-fold dilution series created from a single batch of cDNA from day 18 OBCs derived from a single donor allowed relative comparisons of mRNA copy numbers between donors and experiments. Expression levels were normalized to GAPDH in triplicate.

\section{Microarray analysis}

Human osteogenesis $\mathrm{RT}^{2}$ Profiler $^{\mathrm{Tn}}$ PCR Superarrays (SABiosciences; http://www.sabiosciences.com/PCRArrayPlate.php) were used to monitor 84 different genes associated with osteogenesis. For the matrix study, 500 ng of cDNA were loaded per plate (5 ng/well). Since
FACS sorting yielded limited cell numbers in the coculture experiments, these samples were pre-amplified by 12 rounds of PCR prior to loading them on the Superarray plates. A total of $17.5 \mathrm{ng}$ of mRNA was pre-amplified using $\mathrm{RT}^{2}$ Nano PreAMP cDNA synthesis kits plus the corresponding NanoAmp osteogenic primers (SABiosciences) according to the manufacturer's protocol.

The fluorescence threshold for each plate was adjusted to give an average positive PCR control (PPC) value of $20 \pm 2$ cycle thresholds (CTs). Transcripts whose CTs were $>35$ were assumed to be absent [22]. For preamplified samples, the cut-off CT was 30 , as recommended by the manufacturer (personal communication, SABiosciences representative).

Data analysis was carried out via the SABiosciences web portal. The geometric mean of the housekeeping gene $C T$ values was subtracted from the CT value of each gene of interest for normalization. Housekeeping genes whose $\mathrm{CT}$ values varied by more than two-fold among the conditions were excluded.

\section{Osteogenic differentiation assays}

To visualize matrix mineralization, cultures were stained with $2 \%$ Alizarin Red S (AlzR), pH 4.2 (Rowley Biochemical Institute, Danvers, MA, USA). ALP activity was monitored histochemically using the Fast Blue, leukocyte alkaline phosphatase kit (Sigma, 86R-1KT).

\section{Imaging}

Histochemical staining was imaged at low (5X) and high (63X) magnifications, and as whole-plate scans at a resolution of 2,400 ppi. Fluorescent Live/Dead staining was examined at $10 \times$ magnification and images analyzed using AxioVision software.

\section{D-Differential in-gel electrophoresis (2D-DIGE) and protein identification \\ Sample preparation}

OBCs were cultured from three different MSC donors and lysed as described for the matrix cultures. After the final rinse, matrix proteins were extracted using $7 \mathrm{M}$ urea, $2 \mathrm{M}$ thiourea, $30 \mathrm{mM}$ Tris- $\mathrm{HCl}, 4 \%$ CHAPS, $\mathrm{pH}$ 8.8 and stored at $-80{ }^{\circ} \mathrm{C}$ until use. Proteins were precipitated using the 2D Clean Up Kit (GE Healthcare BioSciences, Pittsburgh, PA, USA) and quantified by the 2D Quant Kit (GE), with pH adjusted to 8.0 - 9.0. A standard was created by mixing together equivalent aliquots of each sample.

\section{CyDye labeling}

Solutions of CyDyes 2, 3, and 5 (GE) in dimethylformamide (Sigma) were added to the samples at final concentrations of $400 \mathrm{pmol}$ per $50 \mu \mathrm{g}$ protein. The standard was labeled with Cy2 while individual samples were labeled 
with either $\mathrm{Cy} 3$ or $\mathrm{Cy} 5$, assigned randomly, for $30 \mathrm{~min}$ on ice in the dark, followed by quenching with lysine (Sigma). Samples were flash frozen and stored at $-80{ }^{\circ} \mathrm{C}$ until use.

\section{First dimension gel rehydration and sample loading}

Thawed samples were equilibrated $(1: 1, \mathrm{v} / \mathrm{v})$ with $2 \times$ sample buffer (7 M urea, $2 \mathrm{M}$ thiourea, $4 \%$ CHAPS, $4 \%$ IPG 3-10, $6.2 \mathrm{mg}$ diothiothreitol/mL) and pooled appropriately. Each mixture was added to rehydration buffer (7 M urea, $2 \mathrm{M}$ thiourea, 4 \% CHAPS, 2 \% IPG 3-10, plus $12 \mu \mathrm{L}$ DeStreak Solution [GE]/mL before use) for a total volume of $340 \mu \mathrm{L}$, and used to rehydrate an Immobiline $^{\text {tw }} 18$ cm IEF DryStrip, pH 3-10 (GE) overnight.

\section{Isoelectric focusing}

A Multiphor II electrophoresis unit (GE Healthcare BioSciences) was used with the following program at $20{ }^{\circ} \mathrm{C}$ in the dark: constant current of $1 \mathrm{~mA}$; constant power of 5 W; $500 \mathrm{~V}$ for $0.01 \mathrm{~h} ; 500 \mathrm{~V}$ for $3 \mathrm{~h}$; gradual ramping from 500 to $3,500 \mathrm{~V}$ over $5 \mathrm{~h}$; and 3,500 V for $12.5 \mathrm{~h}$. Unless used immediately for second dimension electrophoresis, IEF gels were wrapped in plastic, placed in airtight tubes, flash frozen in liquid nitrogen, and stored at $-80{ }^{\circ} \mathrm{C}$ until use.

\section{SDS-polyacrylamide gel electrophoresis}

The second dimension gels were $1 \mathrm{~mm}$ thick, 4-20\% SDS-polyacrylamide gels cast in low-fluorescence glass plates (Jule Biotechnologies, Milford, CT, USA). Electrofocused gels were incubated for $15 \mathrm{~min}$ in the dark in reducing buffer $(0.5 \mathrm{M}$ Tris- $\mathrm{HCl}, \mathrm{pH} \quad 6.8,10 \mathrm{mg}$ dithiothreitol $/ \mathrm{mL}$ ), followed by incubation for $15 \mathrm{~min}$ in alkylation buffer (10\% reduction buffer without dithiothreitol, $6 \mathrm{M}$ urea, $30 \%$ glycerol, $1 \%$ SDS, $25 \mathrm{mg}$ iodoacetamide $/ \mathrm{mL}$ ), placed on the SDS gel, and sealed with 1 $\%$ low-melt agarose. Fluorescent $\mathrm{M}_{\mathrm{r}}$ standards (Sigma) were used. Electrophoresis was run at $25{ }^{\circ} \mathrm{C}(2 \mathrm{~W} / g e l$, $45 \mathrm{~min} ; 17 \mathrm{~W} /$ gel, 3-4 h). Gels were stored moist in the dark at $4{ }^{\circ} \mathrm{C}$ overnight.

CyDye-protein fluorescence was imaged on a Molecular Dynamics Typhoon 9410 Variable Mode Imager at a resolution of 100 pixels $/ \mu \mathrm{m}$. The gel that would be used for picking protein spots ("pick gel") was then stained with SimplySafe Coomassie blue (Invitrogen), and fixed using two to three cycles of a 15 min wash in $10 \%$ ethanol, followed by a $15 \mathrm{~min}$ wash in water. The Coomassie staining of the pick gel was then imaged.

\section{Protein spot comparison: DeCyder ${ }^{\mathrm{TM}}$ analysis}

Gel images were analyzed using $\operatorname{DeCyder}^{\mathrm{ma}}(\mathrm{GE})$ to detect protein spots in each gel. Spots were excluded if they had slopes $>1.3$, areas $<260$ pixels, volumes $<45,000$ pixels, and peak heights $<600$ or $>65,000$ relative fluorescence units. Spots resulting from the $\mathrm{M}_{\mathrm{r}}$ standards were also excluded to prevent them from being used in the statistical analysis of biological variance. The rest of the spots were analyzed manually to ensure accurate discrimination. The software then used the Cy2 standard, included in each gel, to match each protein spot to its related spots in the other gels. This matching was again checked manually and corrected, as needed. Finally, a "pick list" was generated by comparing all occurrences of each spot between gels and choosing those spots whose average volumes were $> \pm 1.5$-fold different from the standard $(\mathrm{p} \leq 0.05)$.

\section{Mass spectrometric identification of protein spots}

Protein spots from the "pick list" were cut out of the gel in $1 \mathrm{~mm}^{2}$ pieces, destained, and digested overnight at 37 ${ }^{\circ} \mathrm{C}$ in trypsin $(0.02 \mu \mathrm{g} / \mu \mathrm{L}$ in $25 \mathrm{mM}$ Tris- $\mathrm{HCl}, \mathrm{pH} 8.0)$ (Promega, Madison, WI, USA) to just cover the gel pieces, with extra buffer on top. Peptides were extracted with $60 \%$ acetonitrile/3 \% trifluoroacetic acid and dried.

Mass spectrometry analysis of gel digest samples was generously performed by Dr. Lewis Pannell (University of Alabama). Samples, dissolved in $15 \mu \mathrm{L} 1 \%$ acetic acid $/ 2 \%$ acetonitrile, were run on an ESI-TRAP mass spectrometer (ThermoElectron LTQ Orbitrap) coupled to an Agilent 1200 nano LC system with a C18 reverse phase column, eluted with $5-90 \%$ acetonitrile (in $0.2 \%$ formic acid) over $40 \mathrm{~min}$. The acquired data files were converted into Mascot generic format (.mgf) and matched against the Swiss Protein (Sprot) Homo sapiens database through the MASCOT search engine (http://www.matrixscience.com). The following additional parameters were used: fixed iodoacetamidation of cysteines, variable deamidation, standard scoring, and requiring at least one unique peptide per protein match ("require bold red"). Mass accuracy for precursor ions was set to $\pm 10 \mathrm{ppm}$ and $\pm 0.6 \mathrm{Da}$ for $\mathrm{MS} / \mathrm{MS}$ fragmentation data. Only proteins with at least three significant peptide matches $(\mathrm{p}<0.05)$ and ion scores $\geq 200$ were considered. Proteins that were identified in gel blanks or that matched the proteins of the $M_{r}$ markers were excluded from further analysis.

\section{Ingenuity analysis}

In silico analysis and compilation of gene expression profiles and 2D-DIGE protein data was performed using Ingenuity Systems software (Qiagen). Changes $\geq 3$-fold of normalized gene expression from MSCs in OM on matrix versus plastic were analyzed with their corresponding $\mathrm{p}$ values $(\leq 0.1)$. For each gene, the fold change at day 6 or day 12 that had the higher value and/or the greater significance was chosen to represent that gene. Proteins identified by mass spectrometry in the 2D gels were analyzed together with their maximum scores from Mascot. 


\section{Statistical analysis}

All statistical comparisons used an unpaired Student's $\mathrm{t}$-test with a $\mathrm{p}$-value of $\leq 0.05$, unless otherwise specified. Graphic portrayals of the data show either standard deviations (SD) or standard errors of the mean (SEM), as specified. Data analysis was performed using Prism (GraphPad Software, La Jolla, CA, USA), Excel (Microsoft, Redmond, WA, USA), FlowJo (Tree Star, Ashland, OR, USA), and ImageQuant (GE).

\section{Results}

\section{MSC/OBC direct contact cultures}

To assess the osteogenic progression of MSCs cultured in direct contact with OBCs, RT-PCR and human osteogenesis
Superarray analyses were performed on FACS-sorted MSCs that had been labeled with DiI and then cocultured with OBCs while undergoing osteogenic differentiation. We first verified that the DiI labeling did not alter MSC gene expression or morphology (Additional file 2: Figure S1). Our results showed that in mixed co-cultures, no obvious morphological differences (Additional file 3: Figure S2) nor consistent changes in gene expression (Additional file 4: Figure S3) were seen $(n=5)$.

\section{MSC Osteogenesis in OBC-Conditioned medium}

To further characterize the nature of OBC-to-MSC signaling, MSCs were cultured in OM that had previously been conditioned by OBCs during days 11-14 of their

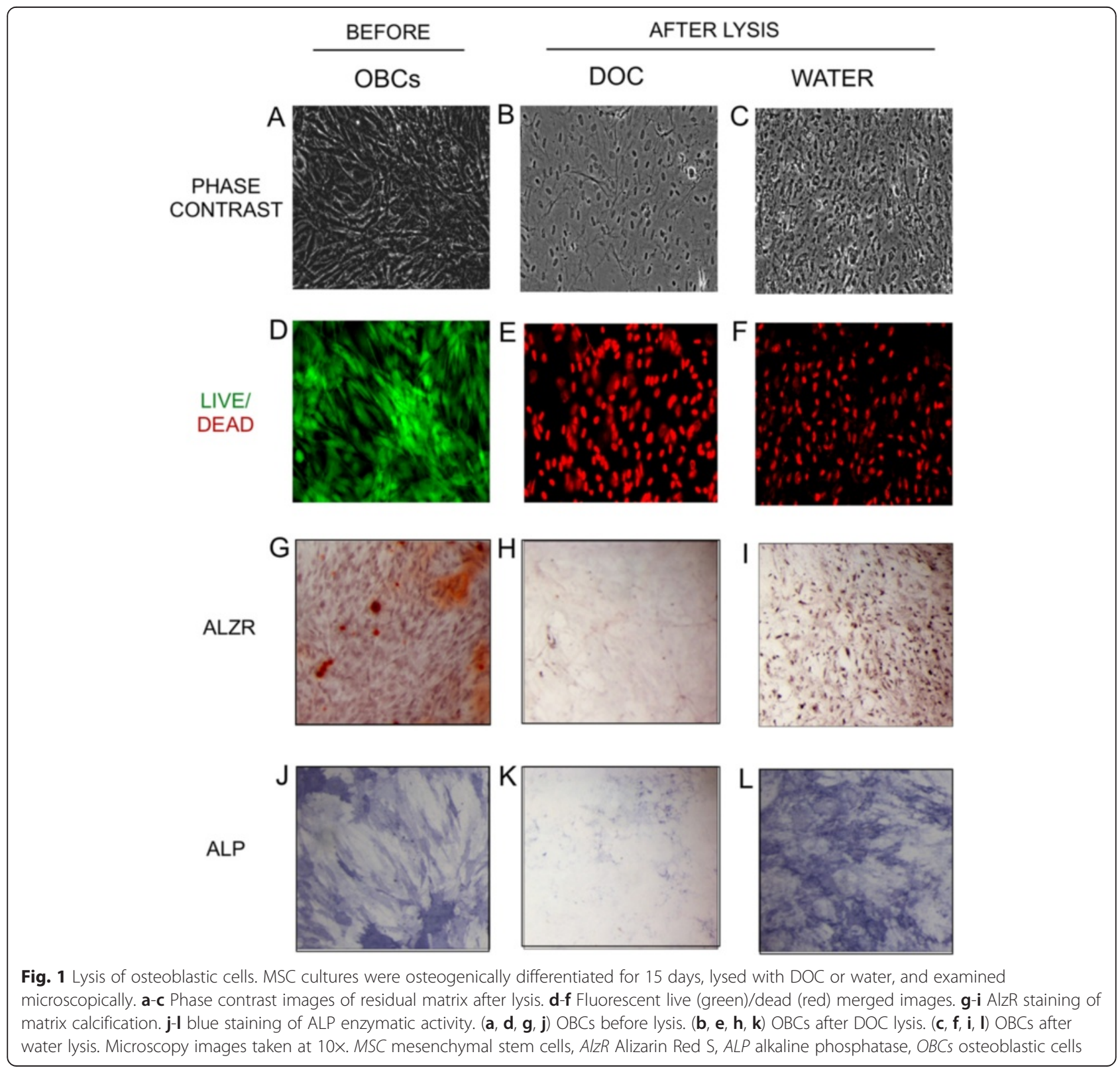


osteogenic progression. MSC expression of OC, ALP, Col I and Runx2, as assayed by real time RT-PCR, was not significantly different in $\mathrm{OBC}$-conditioned $\mathrm{OM}$ versus the AOM control (Additional file 5: Figure S4). None of the changes in gene expression were greater than 1.7-fold and none of them were statistically significant $(n=3)$. This was confirmed by AlzR histological staining of matrix mineralization and ALP histochemical staining (data not shown).

\section{Mineralization of MSCs on OBC Matrix}

Nascent osteoblastic ECM was prepared by lysing OBCs with water or with $0.5 \%$ DOC, producing matrices of distinct complexities. Water lysis was chosen because it does not denature proteins and therefore leaves the ECM mostly intact; DOC was used to decrease the complexity of the ECM by extracting some membrane proteins while being sufficiently mild to leave behind most of the ECM. While these treatments left behind predictably different amounts of matrix proteins and cellular debris (Fig. 1a-c), both lysis methods efficiently killed all OBCs (Fig. 1d-f). AlzR and ALP staining was generally depleted by both lysis methods (Fig. 1g-l), although more ALP activity was retained after water lysis (Fig. 11).

To assess the effects of OBC matrix on MSC osteogenesis, MSCs were seeded on top of both types of matrix. MSCs on water-treated (but not DOC-treated) matrix increased their mineralization compared to those seeded on plastic, as shown by AlzR staining (Fig. 2a-c). While water-treated $\mathrm{OBC}$ matrix could mineralize heavily in OM without live MSCs on top (Fig. 2f), possibly due to the presence of matrix calcium binding proteins, such as osteocalcin, the mineralization seen with MSCs present was substantially more intense (Fig. 2c). This increase was not due to an increase in MSC proliferation on matrix. In fact, calcein fluorescence staining showed that MSCs proliferated slightly less on watertreated $\mathrm{OBC}$ matrix than on plastic, and they proliferated very little when plated on DOC-treated matrix (Fig. 3a). As expected, MSC proliferation was lower in OM than in EM, but, interestingly, this decrease was not apparent when MSCs were plated on water-treated matrix (Fig. 3b).

\section{Gene expression and morphology of MSCs on decellularized OBC matrix}

Although our initial observations based on increased AlzR staining suggested that OBC matrix could enhance MSC osteogenesis, gene expression analysis suggested otherwise. Real time RT-PCR analysis of three key osteoblastic genes, Runx2, ALP, and Col I, consistently showed down-regulation in MSCs seeded on OBC matrix versus plastic $(n=5)$ (Fig. 4). Only OC expression showed no significant differences between plastic and DOC- or water-treated matrix cultures (Fig. 4a). Runx2 levels dropped by nearly $50 \%$ on both matrices at day 6 of culture. While these large decreases were not maintained through day 12, the downward trend remained. ALP levels were only one-third as high on both matrices as on plastic at day 6. Day 12 ALP levels on DOC matrix

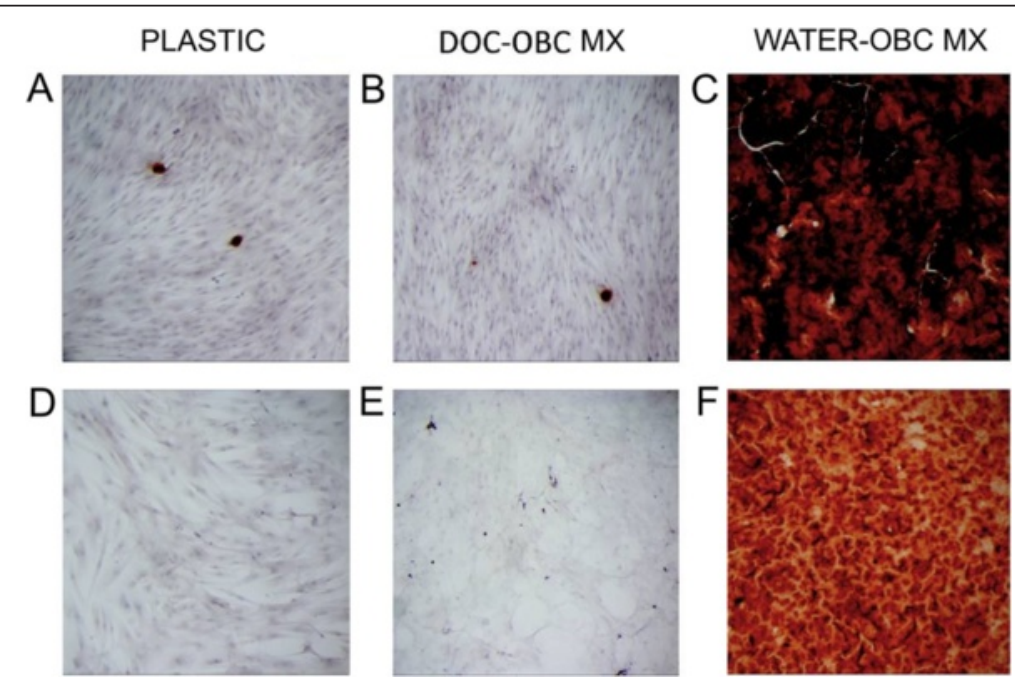

Fig. 2 Water-treated OBC matrix enhances matrix mineralization of MSCS. OBC matrix was prepared from the cells shown in Fig. 1 at day 15 of osteogenic induction. Cultures were stained with AlzR to detect mineralization. MSCs are shown on plastic at day 12 of culture in EM (d) and OM (a). e DOC- and (f) water-treated matrices, without MSCs on top and maintained in OM for 12 days, show that water-treated OBC matrix sometimes remineralizes on its own (f). $\mathbf{b}$ and $\mathbf{c}$ show MSCs seeded on DOC- and water-treated OBC matrix, respectively, after 12 days in OM. DOC-matrix did not affect mineralization compared to cells on plastic (a). While water-treated matrix alone (f) showed a high level of AlzR staining even in the absence of live cells, the presence of MSCs enhanced staining (c). OBC osteoblastic cells, MSC mesenchymal stem cells, AlzR Alizarin Red S, EM expansion medium, OM osteogenic medium 

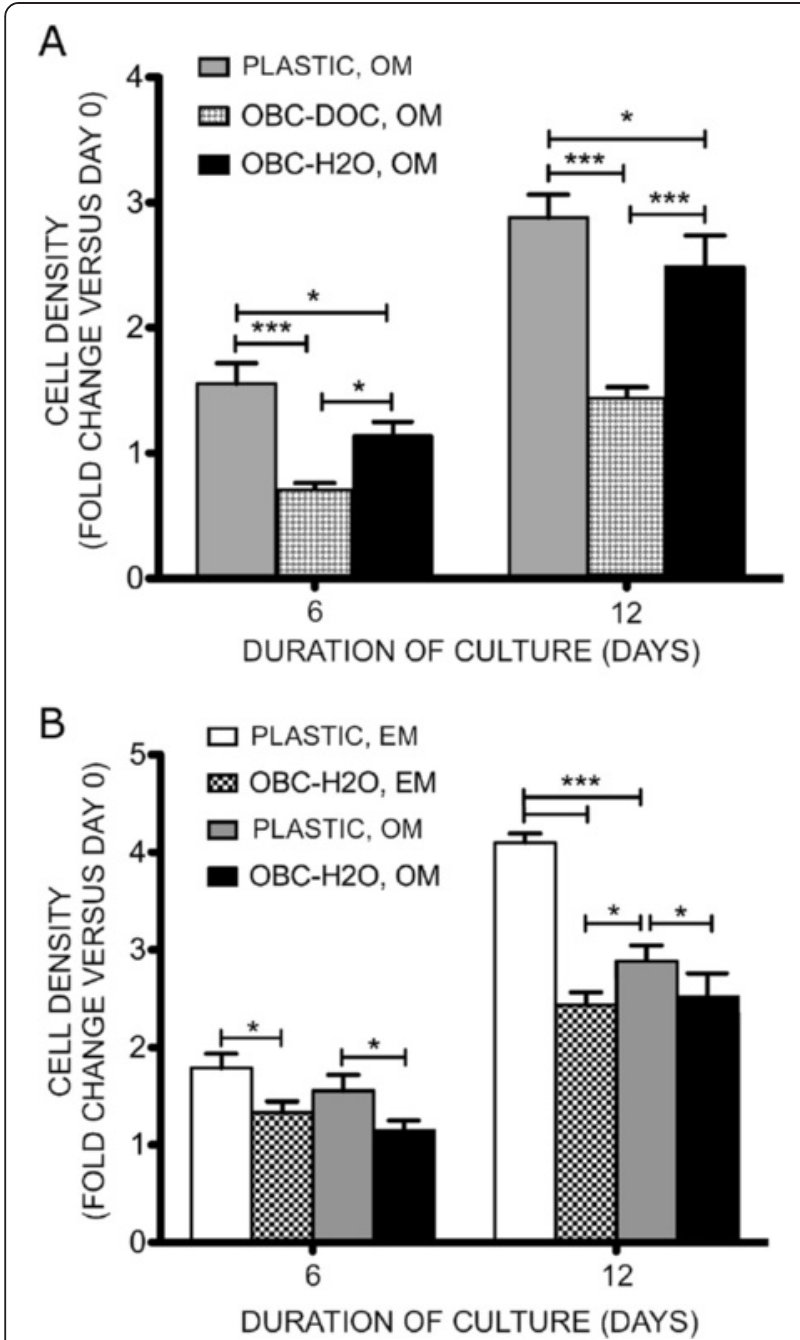

Fig. $3 \mathrm{OBC}$ matrix slows MSC proliferation in EM and OM. MSCs were plated on plastic or DOC-treated or water-treated OBC matrix and maintained in $\mathrm{OM}$ or EM. Their proliferation was examined on culture days 6 and 12. a In OM, MSC proliferation was reduced by 2-fold on DOC-treated OBC matrix and 1.2-fold on water-treated matrix. b MSC proliferation on plastic was 1.3-fold lower in OM than in EM, but this reduced proliferation is absent when comparing cells in $\mathrm{EM}$ and $\mathrm{OM}$ on water-treated $\mathrm{OBC}$ matrix. Fold changes are compared to the pre-culture value and expressed as mean \pm SEM. Data are from a single experiment, representative of three experiments. ${ }^{*}, p<0.5,{ }^{* *}, p<0.01,{ }^{* * *}, p<0.001$. OBC osteoblastic cells, MSC mesenchymal stem cells, EM expansion medium, OM osteogenic medium, SEM standard error of the mean

were similar to those on plastic but levels on water matrix remained at less than $50 \%$ of those on plastic. Finally, Col I levels at day 6 dropped by $50 \%$ on DOC matrix and by $70 \%$ on water matrix. At day 12 , Col I levels on DOC matrix were similar to those on plastic, while those on water matrix were again only one-third as high as those on plastic $(\mathrm{p}=0.1)$. It is noteworthy that for several genes, there was a trend suggesting that water matrix suppressed osteogenic gene expression to a greater extent than DOC matrix: Col I at day 6; OC, ALP and Col I at day 12 (p<0.1) (Fig. 4).

To confirm these data and broaden the number of genes being assessed, we carried out real-time RT-PCR microarray analysis using human osteogenesis Superarrays (see Additional file 6: Figure S5.pdf). Changes $\geq 3$-fold were analyzed. The trends seen previously in the four osteogenic markers (above) were somewhat altered, presumably due to donor variability. Changes in ALP and Runx2 levels did not reach three-fold, although ALP levels were reduced by more than two-fold on water-matrix on days 6 and 12 and on DOC-matrix on day 6. Runx2 levels decreased by 2.3-fold on DOCmatrix on day 6 but all other conditions elicited little change. Twenty-one genes related to osteogenesis displayed $\geq 3$-fold changes in MSCs on matrix, including $\mathrm{OC}$ and $\mathrm{Col}$ I. All of them were down-regulated except CSF2, CSF3, ITGA2, OC and VEGFA. OC was up only on day 6 in MSCs on DOC-matrix. The down-regulated genes included BGN, BMP4, CD36, CDH11, COL1A1, COL1A2, COL4A3, COL10A1, COL11A1, COL12A1, COMP, FGFR2, ICAM1, IGF1, IGF2, and MMP8. Overall, while the Superarray data did not reflect the greater potency of water-treated matrix versus DOC-treated matrix, suppression of MSC osteogenesis by OBC matrix was confirmed.

In support of this observed reduction in osteogenic gene expression, we also noted that the MSCs cultured on OBC matrix did not assume an osteoblastic morphology. On plastic, MSCs showed a marked transformation in shape from long and fibroblastic in EM (Fig. 5a) to bunched and cuboidal in OM (Fig. 5b). However, when these same cells were cultured in $\mathrm{OM}$ on either DOC- or water-treated OBC matrix, their morphology remained fibroblastic even through day 12 (Fig. $5 \mathrm{c}$ and d, respectively).

\section{Specificity of the effect of OBC-derived matrix}

Finally, it should be noted that the observed effects of OBC matrix on MSC osteogenesis appeared to be OBCspecific. This was confirmed by comparing the effect of OBC matrix on MSC osteogenesis to that of matrix derived from human foreskin fibroblasts (HFF), prepared using an identical water lysis decellularization protocol. As shown in Additional file 7: Figure S6, HFF-derived matrix did not suppress the ALP level as effectively as $\mathrm{OBC}$-derived matrix.

\section{OBC matrix protein identification by 2D-DIGE}

To begin identifying the proteins responsible for the observed effects on MSC osteogenic differentiation, proteins found in DOC and water matrix were compared through 2D-DIGE (Fig. 6). The amount of each protein from three samples of each matrix type was compared 


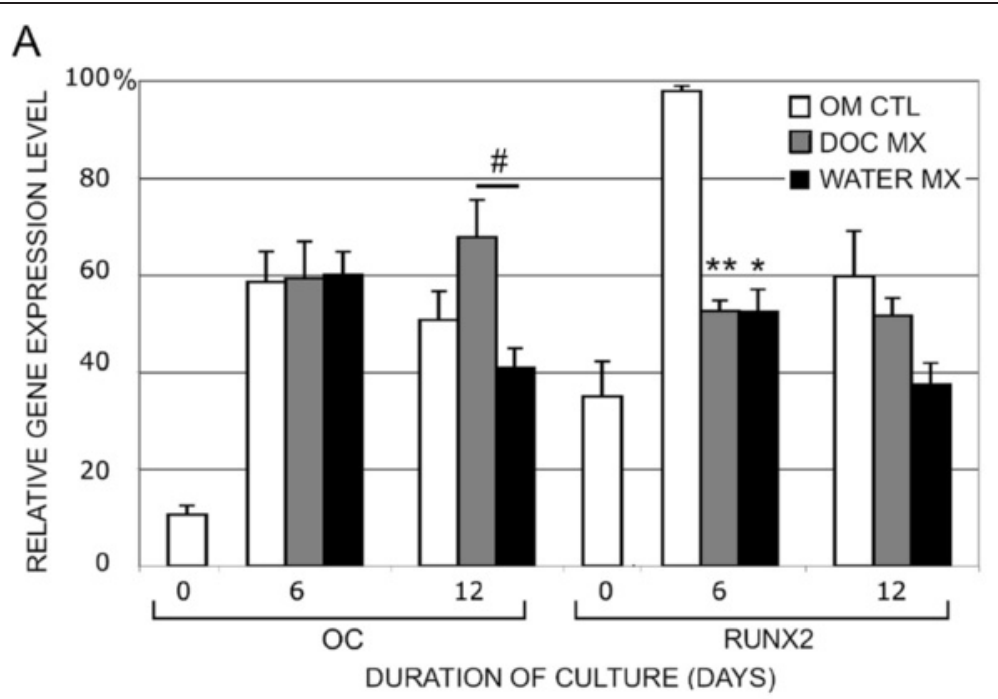

B

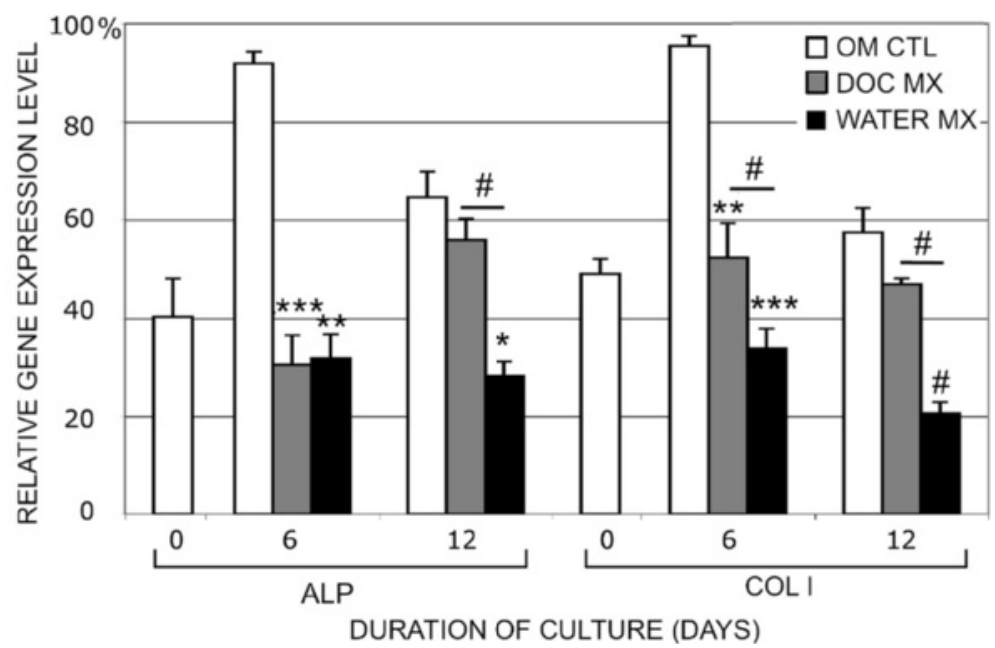

Fig. $4 \mathrm{OBC}$ matrix suppresses MSC expression of osteogenic genes. MSCs were seeded on top of OBC matrix (treated with water or DOC) and cultured in OM for 6 and 12 days. Gene expression of $\mathbf{a}$ OC, Runx2, b ALP, and Coll was assayed by real-time RT-PCR. Expression levels were normalized to GAPDH and shown as a percentage of the maximum level within each experiment. Values are means \pm SEM of five experiments. Asterisks indicate significance between experimental conditions and the $\mathrm{OM}$ control. Bars show significance between matrix conditions. \#, $\mathrm{p}<0.1,{ }^{*}, \mathrm{p}<0.05,{ }^{*}, \mathrm{p}<0.01$, ${ }^{* * *}, \mathrm{p}<0.001$. OBC osteoblastic cells, MSC mesenchymal stem cells, OM osteogenic medium, RT-PCR reverse transcription-polymerase chain reaction, SEM standard error of the mean

to the protein standard contained within each gel. Their relative amounts were plotted on graphs (Fig. 7) and compared. Table 1 shows the "pick list", the 29 gel spots found by DeCyder to be at least 1.5 -fold more abundant in one matrix versus the other $(\mathrm{p}<0.05)$. Table 2 lists the proteins identified by mass spectrometry from the gel spots on the "pick list." The most likely candidate proteins, due to their known extracellular location, are those of the ECM, including collagen type VI $\alpha 1$ and $\alpha 3$ (COL6A1, COL6A3), elastin microfibril interfacer (EMILIN1), EGF-containing fibulin-like extracellular matrix protein (EFEMP2), heat shock-induced serine protease HTRA1, and TGF- $\beta$-induced protein (TGFBI). Several plasma membrane proteins are also strong candidates, including annexins A1, A2 and A6 (ANXA1, ANXA2, ANXA6), flotillin (FLOT1), and fibronectin I (FN1). COL6A1 and A3, EMILIN1, and FN1 were identified in spots that were more intense in DOC-treated matrix, while the others plus COL6A3 were more abundant in water-treated matrix. (COL6A3 was present in more than one protein spot.) These 11 proteins were organized by Ingenuity into functional groups. Groups for cell morphology, cellular assembly and organization, cellular growth and proliferation, cell-to-cell signaling and interaction, and cellular movement each included at least five of the focus proteins and received p-values of $<0.05$. Their putative relationships with each other, and with the osteoblastic genes RUNX2, OC (BGLAP), COL1A2, and 
A

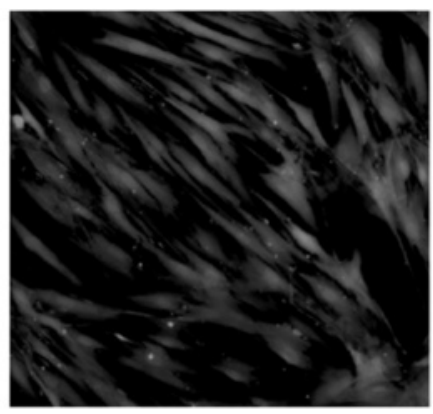

C

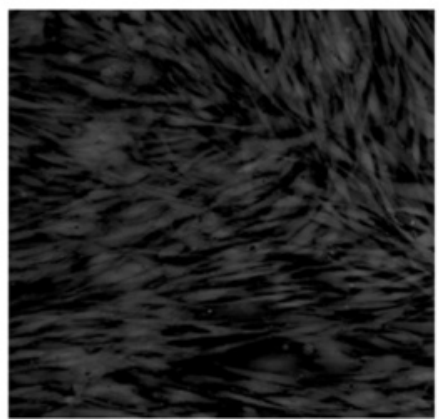

$\mathrm{B}$

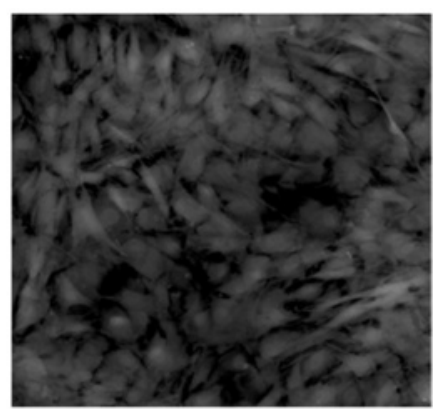

D

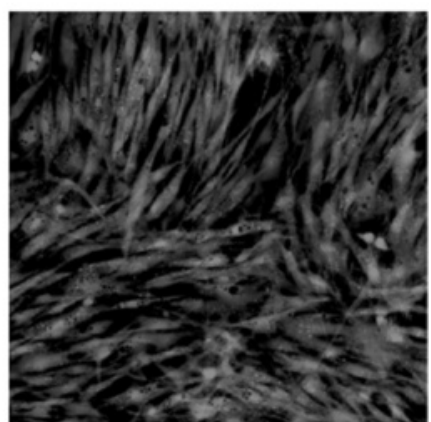

Fig. 5 OBC matrix preserves the naïve, fibroblastic morphology of MSCs. Fluorescence microscopy of Calcein AM-labeled cells shows that, even at day 12, MSCs cultured in OM and seeded on OBC matrices (c, DOC- and $\mathbf{d}$, water-treated) retain their fibroblastic morphology, like MSCs cultured in EM on plastic (a), instead of becoming cuboidal, like cells cultured in OM on plastic (b). a, b Viewed at day 6. OBC osteoblastic cells, MSC mesenchymal stem cells, OM osteogenic medium, EM expansion medium

ALP(L), are shown in Fig. 8 (also see Additional file 8: Table S2). As few additional proteins as possible were added (by Ingenuity) to allow each protein of interest to have at least one connection to the network.

\section{Discussion}

In this study, we have attempted to model the bone marrow niche of adult MSCs in vitro by generating a nascent osteoblast environment and testing its effect on MSC osteogenesis. When RT-PCR was used after FACS separation of cocultured MSCs, no differences were detected in osteogenic transcript levels between MSCs cultured with and without contact with OBCs. These results are corroborated by the findings of Wang et al. [15] in a similar study using mouse cells. These authors mixed MC3T3-E1 mouse osteoprogenitor cells with MSCs from GFP-transgenic mice, cultured them in OM at a plating density of $5,000 / \mathrm{cm}^{2}$ for 21 days, then FACS sorted the MSCs based on green fluorescent protein (GFP) fluorescence, and analyzed the transcript levels of osteogenic genes. Their results showed that direct cellcell contact with the osteoblastic cells did not significantly alter the osteogenic differentiation of the MSCs.

As in our study, Wang et al. [15] also examined the effects of OB-secreted proteins on the osteogenesis of MSCs. When mouse MSCs were cultured indirectly with MC3T3 cells in OM using Transwell inserts, the proliferation of neither cell type was affected, but matrix calcification was enhanced and several osteogenic gene transcript levels were significantly increased. The differences in our results may be related to the developmental stage of the OBs used: the mouse MC3T3 osteogenic cell line is derived from newborn mouse calvaria, while the $\mathrm{OBCs}$ used here are recently derived from adult human MSCs. It is also known that mouse and human MSCs do not respond equivalently to all osteogenic stimuli [23]. Additionally, other studies have also reported a lack of osteo-induction by OB-secreted factors. For example, Gerstenfeld et al. [11] found that $\mathrm{C} 3 \mathrm{H} 10 \mathrm{~T}^{1} / 2$ mouse embryonic MSCs did not increase their expression of OC when co-cultured in Transwells with chick embryonic calvarial OBs.

A number of studies have assessed the effects of various ECMs and their individual components on the osteogenic differentiation of mesenchymal cells [24, 25]. Although the experimental systems were usually simplified to examine the effects of a single ECM protein on MSC osteogenesis, many of the studies reported conflicting results. Shi et al. [21] found that Col I-coated plates stimulated Col I, ALP and osteopontin gene expression in rat neonatal calvarial cells (ROB-C26) without osteoinductive medium, but the Col I matrix was not sufficient to induce ALP activity or the expression of TGF$\alpha 1$, TGF- $\beta 2$ or BMP-6. Salasznyk et al. [26] concluded similarly that human MSCs can be induced to differentiate into OBs through contact with Col I or vitronectin, 


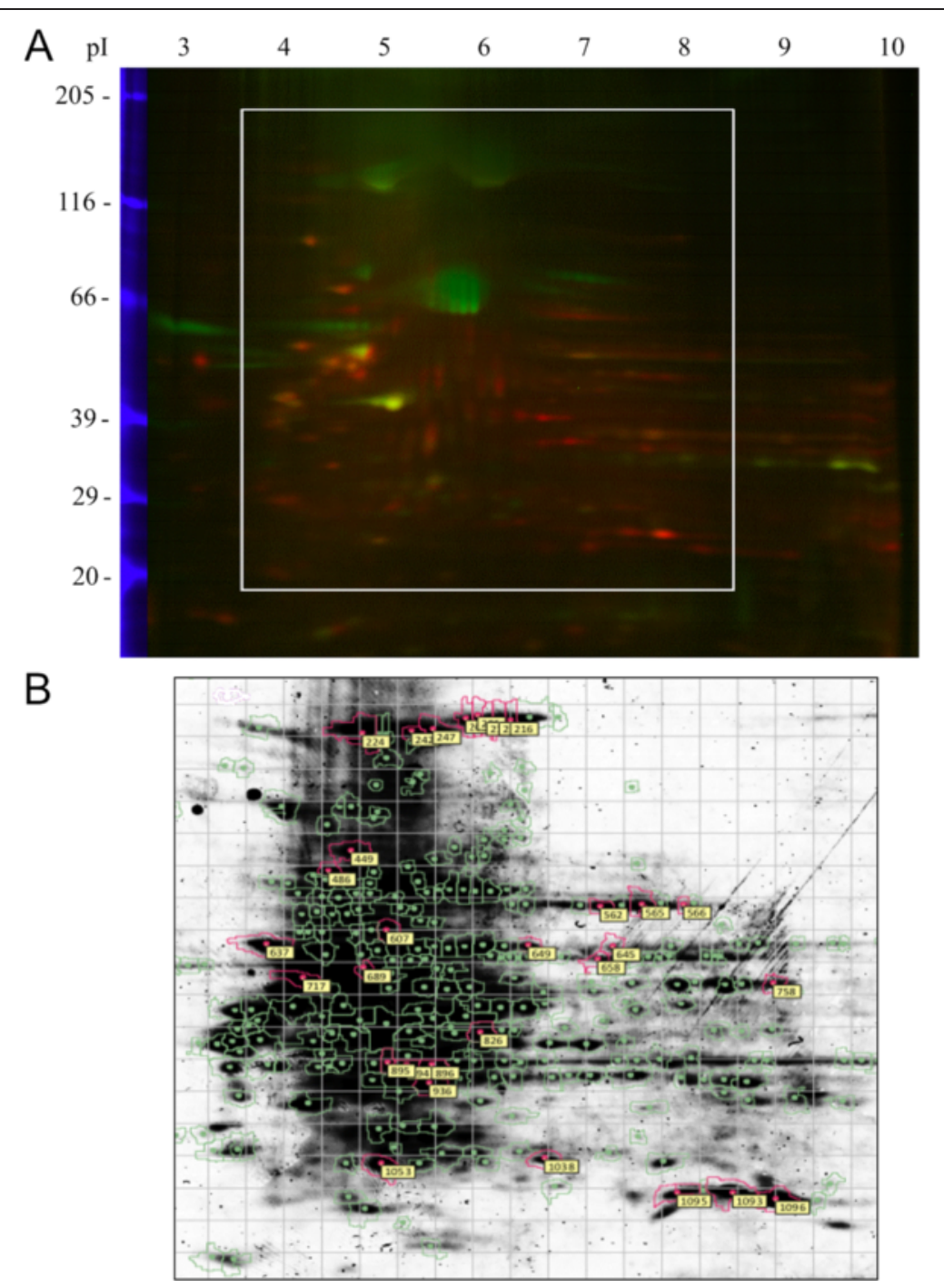

Fig. 6 2D-DIGE analysis of OBC matrix proteins. a A fluorescent image of a representative 2D gel. Blue bands at left represent fluorescent $M_{r}$ standards. DOC-treated OBC matrix proteins were labeled with Cy3 (green); water-lysed OBC matrix proteins with Cy5 (red). The linear, immobilized IEF gradient gel is at the top with the acidic end $(\mathrm{pH} 3)$ at the left and the basic end $(\mathrm{pH} 10)$ at the right. The white box shows the approximate area of the Coomassie-stained gel shown in (b) from which the protein spots were excised. Excised spots are circled in pink and labeled with a spot number. 2D-DIGE 2D-differential in-gel electrophoresis, OBC osteoblastic cells, IEF isoelectric focusing gel

without osteogenic supplements, as assessed via mineralization and Col I, OPN and ALP mRNA. Cool and Nurcombe [27], however, saw no differences in proliferation, ALP activity or Runx2, Col I or OC mRNA levels in murine MSCs seeded on Col I, FN1 or laminin substrates and cultured in OM. (Note: culturing in EM was not tested.) Nor did Heckmann et al. [28] observe an induction of $\mathrm{OC}$ or Col I expression when human MSCs were cultured on a three-dimensional Col I matrix. There is thus no obvious consensus in the literature regarding the effects of any single ECM protein on MSC osteogenesis.

While these apparent conflicts may be related to differences of species, substrates or culture media, these studies by their very nature are overly reductionistic in terms of mimicking the in vivo environment since the ECM is a complex mixture of multiple components, deposited in temporospatially specific configurations and proportions that are important for their biological activities. To better approximate the in vivo niche, we chose to examine the activity of the matrix laid down by nascent osteoblastic cells. The native configuration of the OBC ECM is preserved by keeping it on the original culture dishes, without decalcification, fixation, or extraction. In this context, it is instructive to review the classic work of Urist on demineralized bone matrix (DBM) [20]. In Urist's studies, adult human and rabbit bones were lyophilized and decalcified and implanted into various muscles and bone defects. The DBM induced new bone 

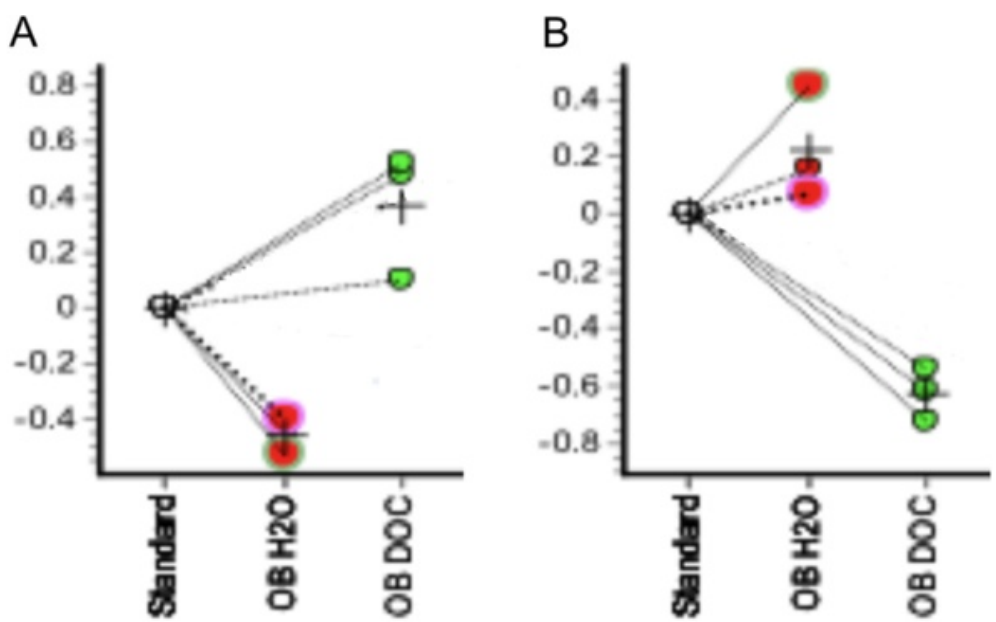

Fig. 7 Graphs showing the relative abundance of matrix proteins from different spots. a Spot 449. b Spot 1096

formation within the rings of decalcified matrix. However, a later study showed that the principal inducers responsible for DBM-induced osteogenesis were BMPs sequestered in the bone matrix [29]. This was further verified by Becerra et al. [30] who found that DBM could also enhance MSC osteogenesis indirectly through Transwell inserts. The fundamental difference between DBM and the ECM used here is one of age and structure. As bone matures over time, growth factors, such as BMPs, are sequestered within the bone matrix, particularly in the mature trabecular and cortical bone, as new layers of ECM are deposited and mineralized. The new matrix used here, synthesized by nascent OBCs and grown on a two-dimensional surface, is less likely to entrap growth factors. It more closely mimics that laid down by bone-lining cells at the endosteal surface of the bone marrow cavity, i.e., it is similar to the osteoblastic matrix that MSCs likely encounter in vivo. Enhancement of MSC osteogenesis seen with mature bone matrix likely mimics what MSCs experience during fracture healing when trabecular or cortical bone is exposed along with its matrix and bound growth factors [31, 32]. MSCs, recruited to the site, thus come into contact with the growth factor-laden mature bone, which then induces them to begin osteogenic differentiation to repair the fracture.

One other study elegantly demonstrates the importance of the maturity of the $\mathrm{OB}$ matrix being studied [33]. ECM was produced by neonatal rat calvarial cells (ROB-C26) cultured with or without retinoic acid, which induces osteogenesis in these cells. ECM made by the more osteoblastic cells was able to induce osteogenesis in naïve C26 cells in vitro and in vivo. However, ECM synthesized by $\mathrm{C} 26$ cells in the absence of retinoic acid was only able to partially stimulate osteogenesis in vitro and not at all in vivo.
Furthermore, Chen et al. [34] showed that ECM from murine MSCs themselves enhanced MSC proliferation and slowed their spontaneous osteogenic differentiation, while enhancing their tri-lineage plasticity. A second study confirms this in human MSCs and identifies several of the proteins present in the ECM (Col I, Col II, FN, byglycan, decorin, perlecan, and laminin) [35].

The fact that MSCs' own matrix can help maintain their stemness [35] is particularly interesting, not only because of its implications for the MSC niche, but also because it suggests that "concentrations" of ECM are important. Because MSC ECM is always available to MSCs, if this contact were sufficient to maintain their stemness, they would have to halt production of ECM proteins and withdraw from their ECM before differentiating. While this could be one explanation, there could also be thresholds of MSC-ECM interactions that must be reached before certain effects occur. Indeed, a similar idea was proposed by Volloch and Olsen [36] regarding the effect that the "density" of integrin-binding sites within various matrices has on MSC differentiation.

In addition to these quantitative thresholds of interacting ECM, apparently achieved in the OBC matrix studied here, there are likely qualitative characteristics of the OBC matrix, i.e., specific components that are important for the control of the differentiation activities of MSCs. Therefore, we compared the protein compositions of the DOC- and water-lysed OBC matrices using 2D-DIGE. Eleven focus proteins were chosen because of their characterization as ECM or membrane proteins, which makes them most likely to be in contact with MSCs in vivo. These were FN1, COL6A1, COL6A3, ANXA1, ANXA2, ANXA6, HTRA1, flotillin (FLOT1), EMILIN1, EFEMP2, and TGFBI. Several of these proteins have already been implicated in stem cell functions or osteogenesis. FN1, for example, was found in the 
Table 1 "Pick List" of statistically significant protein spots for identification

\begin{tabular}{|c|c|c|c|c|c|c|}
\hline Spot No. & Avg. ratio & $\mathrm{p}$-value (t-test) & Spot Vol. & $\mathrm{pl}$ & $\mathrm{Mr}_{\mathrm{r}}$ & Match quality \\
\hline 201 & 5.32 & 0.019 & N/A & 5.65 & 133,581 & 1.80 \\
\hline 203 & 5.69 & 0.015 & $1,809,098$ & 5.72 & 133,294 & 2.38 \\
\hline 208 & 6.21 & 0.015 & $1,387,720$ & 5.81 & 132,723 & 1.78 \\
\hline 210 & 7.48 & 0.015 & $2,038,969$ & 5.90 & 131,588 & 0.74 \\
\hline 214 & 7.7 & 0.015 & $2,700,438$ & 6.00 & 130,462 & 0.52 \\
\hline 216 & 7.72 & 0.015 & $2,774,451$ & 6.09 & 129,903 & 0.47 \\
\hline 224 & 5.93 & 0.015 & $11,334,140$ & 4.82 & 127,965 & 2.77 \\
\hline 242 & 6.59 & 0.019 & $1,651,536$ & 5.24 & 121,536 & 3.41 \\
\hline 247 & 4.71 & 0.015 & $2,109,428$ & 5.39 & 120,497 & 5.05 \\
\hline 449 & 7.28 & 0.019 & $1,501,211$ & 4.76 & 82,040 & 1.30 \\
\hline 486 & -1.6 & 0.038 & $1,347,174$ & 4.59 & 75,936 & 2.60 \\
\hline 562 & -3.64 & 0.026 & $1,435,516$ & 6.56 & 66,327 & 2.55 \\
\hline 565 & -3.31 & 0.030 & $2,230,394$ & 6.85 & 66,184 & 1.05 \\
\hline 566 & -1.73 & 0.043 & 258,223 & 7.15 & 66,184 & 2.82 \\
\hline 607 & -2.65 & 0.015 & $1,380,551$ & 5.02 & 61,260 & 3.09 \\
\hline 637 & -2.67 & 0.036 & $4,584,544$ & 4.16 & 57,933 & 0.77 \\
\hline 649 & -4.96 & 0.015 & 746,894 & 6.09 & 57,561 & 12.13 \\
\hline 658 & -1.52 & 0.031 & 773,745 & 6.43 & 56,824 & 3.03 \\
\hline 689 & -1.73 & 0.049 & $3,281,833$ & 4.82 & 54,319 & 0.67 \\
\hline 717 & -2.11 & 0.041 & $5,864,175$ & 4.42 & 51,923 & 0.70 \\
\hline 758 & -2.09 & 0.041 & 750,800 & 7.99 & 48,788 & 3.34 \\
\hline 826 & -2.69 & 0.034 & $2,653,198$ & 5.71 & 42,890 & 2.37 \\
\hline 894 & -1.93 & 0.015 & $1,912,332$ & 5.17 & 38,606 & 5.09 \\
\hline 895 & -1.83 & 0.041 & 694,589 & 4.97 & 38,275 & 2.33 \\
\hline 896 & -3.09 & 0.015 & $5,361,677$ & 5.35 & 38,440 & 2.96 \\
\hline 1053 & -2.63 & 0.036 & $2,984,453$ & 4.99 & 27,203 & 1.65 \\
\hline 1093 & -7.66 & 0.015 & $6,128,338$ & 7.30 & 24,017 & 2.46 \\
\hline 1095 & -4.59 & 0.023 & $1,765,854$ & 6.92 & 23,914 & 1.91 \\
\hline 1096 & -7.55 & 0.015 & $13,937,178$ & 7.60 & 23,812 & 0.52 \\
\hline
\end{tabular}

DeCyder-generated list of proteins whose abundances vary by at least \pm 1.5 -fold $(p \leq 0.05)$ between DOC- and water-treated OBC matrices. Columns show (left to right): numbers assigned to each spot on the gel; average ratios between spot volumes (DOC/water); p-values corresponding to those ratios; maximum spot volumes (pixels); approximate pls and $\mathrm{M}_{\mathrm{r}}$ (Daltons) based on position within the gel; and match quality, a measure of consistency between a spot's replicates in different gels (lower is better). Spots above the double line are more abundant in DOC matrix, below, in water matrix

$O B C$ osteoblastic cell

MSC ECM reported in the study mentioned above to suppress MSC osteogenesis [34]. It has also been used to coat tissue culture dishes to enhance the proliferation and plasticity of a subpopulation of MSCs $[5,37]$. ANXA1 and 2 are up-regulated in amputated tadpole tails undergoing regeneration [38]. Interestingly, they were also both identified in a proteomic analysis of mouse embryonic fibroblasts, which are the feeder layers cells used to maintain embryonic stem cells in vitro [39].

TGFBI binds collagen types I, II and IV and is expressed in most tissues [40]. It has been shown to be highly expressed in HSCs that adhere well to MSCs [41].
This observation is significant because the binding of HSCs to MSCs has been implicated in the maintenance of the HSC phenotype in culture [42]. In addition, when TGFBI is exogenously added to periodontal ligament cells, it can inhibit their mineralization, suggesting an anti-osteogenic function [43]. Recent research shows that HTRA1 may play a similar role since it inhibited mineral deposition in immortalized murine OBs (2 T3 cells) even in the presence of BMP-2 [44]. The same study also showed that its overexpression reduced levels of Runx2 and Col I mRNA. However, further research, using human MSCs, showed an opposite effect for HTRA1 [45], although it did confirm that HTRA1 
Table 2 Identities of Proteins from "Pick List"

\begin{tabular}{|c|c|c|c|c|c|c|c|}
\hline & Symbol & Entrez Gene Name & Found in Spots: & Mx & Max Score & $\mathrm{pl}$ & $M_{r}$ \\
\hline \multirow[t]{24}{*}{ CYTOPLASM } & ACTA2 & actin, alpha 2 , smooth muscle, aorta & $826,894-6,1053$ & W & 348 & 5.23 & 42,381 \\
\hline & ALDH1B1 & aldehyde dehydrogenase 1 family, member B1 & 658 & W & 283 & 6.36 & 57,658 \\
\hline & AKR1C1 & aldo-keto reductase family 1 , member $\mathrm{C} 1$ & 894 & W & 240 & 8.02 & 37,221 \\
\hline & ATP5A1 & ATP synthase, $\mathrm{H}+$ transport, mitoch F1 complex, alpha 1 & 658 & W & 867 & 9.16 & 59,828 \\
\hline & ATP5B & $\begin{array}{l}\text { ATP synthase, H+ transport, mitoch F1 complex, } \\
\text { beta }\end{array}$ & 689 & W & 683 & 5.26 & 56,525 \\
\hline & CKAP4 & cytoskeleton-associated protein 4 & 717 & W & 821 & 5.63 & 66,097 \\
\hline & ENO1 & enolase 1 , alpha & 758,759 & W & 532 & 7.01 & 47,481 \\
\hline & ENO3 & enolase 3 , beta, muscle & 758 & W & 246 & 7.59 & 47,299 \\
\hline & EIF3B & eukaryotic translation initiation factor 3 , subunit B & 896 & W & 213 & 5.38 & 36,878 \\
\hline & $\mathrm{FH}$ & fumarate hydratase & 758,759 & W & 290 & 8.85 & 54,773 \\
\hline & HSP90B1 & heat schock protein $90 \mathrm{kDa}$ beta (Grp94), member 1 & $449,636,637$ & B & 306 & 4.76 & 92,696 \\
\hline & HSPB1 & heat shock $27 \mathrm{kDa}$ protein 1 & 1053 & W & 315 & 5.98 & 22,826 \\
\hline & HSPD1 & heat shock 60kDa protein 1 (chaperonin) & 607 & W & 390 & 5.83 & 60,813 \\
\hline & HSPA5 & heat shock $70 \mathrm{kDa}$ protein 5 (glucose-regulated) & 449,486 & B & 1483 & 5.07 & 72,402 \\
\hline & IKIP & IKK interacting protein & 717 & W & 487 & 9.21 & 39,399 \\
\hline & PRDX1 & peroxiredoxin 1 & 1093 & W & 363 & 8.27 & 22,324 \\
\hline & $\mathrm{P} 4 \mathrm{HB}$ & prolyl 4-hydroxylase, beta polypeptide & $201,607,636$ & B & 1116 & 4.76 & 57,480 \\
\hline & PSMD13 & proteasome (prosome, macropain) $26 \mathrm{~S}$ subunit, 13 & 826 & W & 219 & 5.71 & 42,872 \\
\hline & PDIA3 & protein disulfide isomerase family $A$, member 3 & $647-9$ & W & 706 & 5.98 & 57,146 \\
\hline & PDIA6 & protein disulfide isomerase family A, member 6 & 689 & W & 395 & 5.35 & 48,207 \\
\hline & PDHB & pyruvate dehydrogenase (lipoamide) beta & 896 & W & 202 & 6.20 & 39,550 \\
\hline & PKM2 & pyruvate kinase, muscle & 607 & W & 341 & 7.96 & 58,470 \\
\hline & SOD2 & superoxide dismutase 2 , mitochondrial & $1093-6$ & W & 347 & 8.35 & 24,878 \\
\hline & TUBA1A & tubulin, alpha $1 \mathrm{~A}$ & 689,894 & W & 494 & 4.94 & 50,788 \\
\hline \multirow[t]{6}{*}{ ECM } & COL6A1 & collagen, type $\mathrm{VI}$, alpha 1 & $201,203,208,210,224,242,247$ & D & 1432 & 5.26 & 109,602 \\
\hline & COL6A3 & collagen, type VI, alpha 3 & $247,607,649$ & B & 321 & 6.26 & 345,163 \\
\hline & EFEMP2 & EGF-containing fibulin-like ECM protein 2 & 636 & W & 297 & 4.79 & 51,725 \\
\hline & EMILIN1 & elastin microfibril interfacer 1 & $224-6,242,247$ & $\mathrm{D}$ & 462 & 5.07 & 107,913 \\
\hline & HTRA1 & HtrA serine peptidase 1 & 637 & W & 267 & 8.09 & 52,167 \\
\hline & TGFBI & transforming growth factor, beta-induced, $68 \mathrm{kDa}$ & 486 & W & 247 & 7.62 & 75,261 \\
\hline \multirow[t]{5}{*}{ PM } & ANXA1 & annexin A1 & $894-6$ & W & 397 & 6.57 & 38,918 \\
\hline & ANXA2 & annexin $\mathrm{A} 2$ & $894-6$ & W & 1201 & 8.44 & 36,950 \\
\hline & ANXA6 & annexin A6 & 486 & W & 265 & 5.42 & 76,168 \\
\hline & FN1 & fibronectin 1 & all but 1093-96 & $\mathrm{D}$ & 2242 & 5.45 & 266,034 \\
\hline & FLOT1 & flotillin 1 & 758 & W & 496 & 7.08 & 47,554 \\
\hline \multirow[t]{2}{*}{ NU } & CRYAB & crystallin, alpha B & $1093-6$ & W & 244 & 6.76 & 20,146 \\
\hline & LMNA & $\operatorname{lamin} A / C$ & $561-66$ & W & 1179 & 6.57 & 74,380 \\
\hline
\end{tabular}

Columns show (left to right): the number(s) of the spot(s) where a given protein was found; the type of matrix in which the protein was more abundant $\left(\mathrm{D}=\mathrm{DOC}, \mathrm{W}=\right.$ water, $\mathrm{B}=$ = both); maximum Mascot identity score from mass spectrometry; and theoretical pls and $\mathrm{M}_{\mathrm{r}}$ values determined by Mascot from the protein sequences. Bolded text indicates that the approximate pl and/or $\mathrm{M}_{\mathrm{r}}$ of the spot in which the protein was found match its theoretical values. Proteins are grouped by subcellular location based on Ingenuity's database $N U$ nucleus, ECM extracellular matrix, PM plasma membrane 


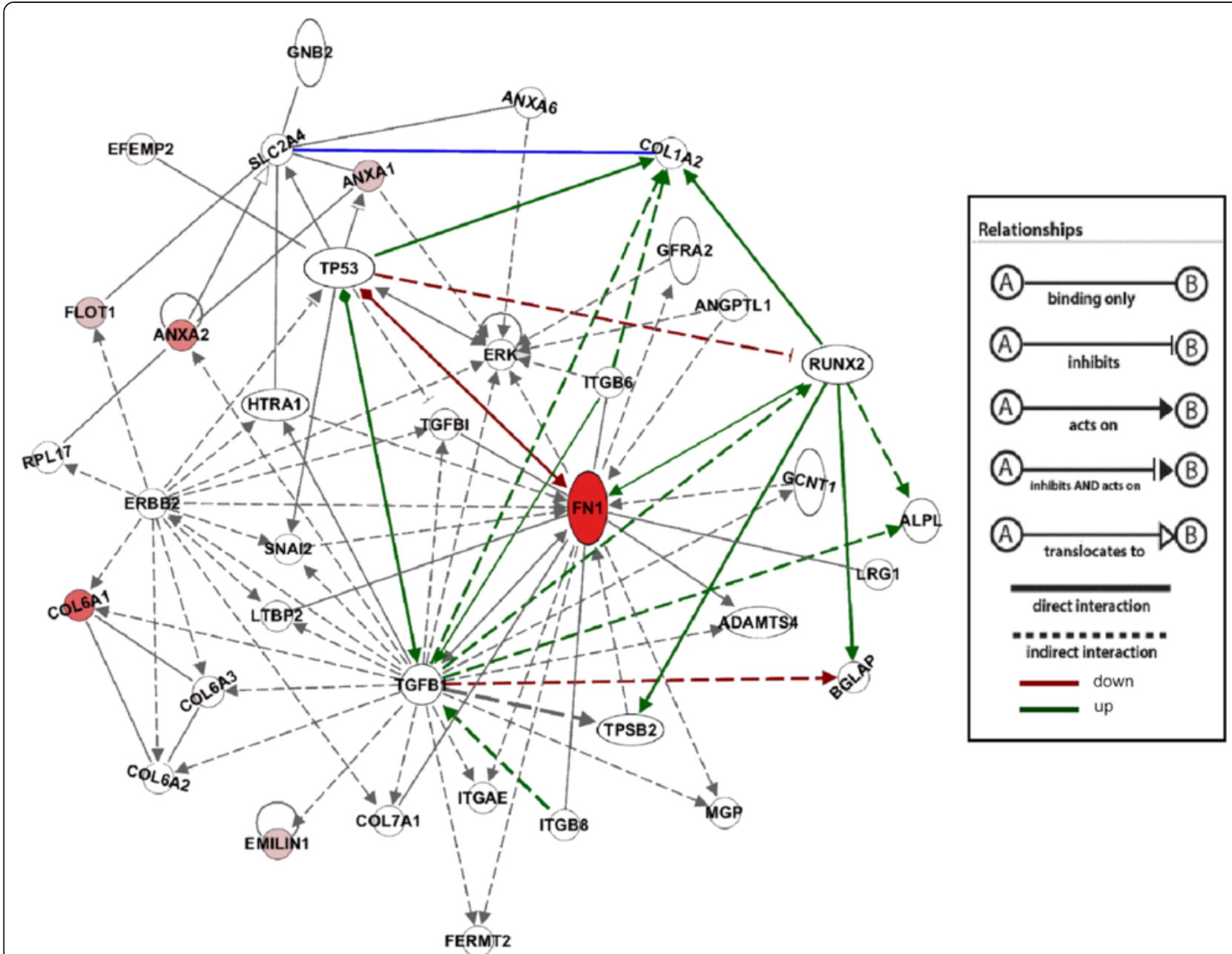

Fig. 8 Connections to regulators of osteogenesis and cellular proliferation exhibited by proteins identified by 2D-DIGE. This network, generated by Ingenuity ${ }^{\oplus}$, portrays relationships described in the literature between all of the proteins identified by 2D-DIGE. Runx2 was added to emphasize the participation of these proteins in the osteogenic pathway. The proteins from the gel spots are colored in varying shades of red relative to the match score they received from Mascot. Together with TGF- $\beta 1$, Runx2 and TP53 are hubs for regulation of osteogenesis and cellular proliferation. (Note: Gray arrows indicate action, not up/down-regulation. Only lines leading to and away from the four focus genes are color-coded.) Protein symbols are listed in (Additional file 8: Table S2). 2D-DIGE 2D-differential in-gel electrophoresis

secretion from MSCs increases as they undergo osteogenesis and, in mice, it is found mostly in areas of new bone formation after fracture.

EMILIN1 has not yet been linked to bone tissues but is known to bind pro-TGF- $\beta$, a key regulator of osteogenesis, in the extracellular space of blood vessels [46]. This binding inhibits the maturation of TGF- $\beta$, the purpose of which may be the prevention of fibrosis due to Col I buildup [46].

To date, several studies have shown that ECMs generated by various cell types in vitro, including MSCs themselves, can encourage MSC stemness and suppress their differentiation [34, 47-50]. It is unlikely that there is a single MSC niche produced by a single cell type. Indeed MSCs are found throughout the body in various tissues. To discover which proteins are most important in maintaining and expanding MSCs, one approach would be to compare the proteins present in OBC ECM to those found in other stemness-enhancing ECMs. Since the ECM generated by MSCs of older mice has been shown to be less efficient in maintaining their stemness [51], we suggest that the protein makeup of ECMs from human donors of various ages be compared as well.

\section{Conclusions}

In summary, our study has shown an osteo-inhibitory function for $\mathrm{OBC}$ matrix laid down in vitro by nascent osteoblasts derived from osteogenically differentiated MSCs. The OBC matrix is likely to be similar to that laid down by newly-formed, active OBs that line the endosteal surface in the bone marrow milieu. Since only MSC osteogenesis is examined here, whether the "niche effect" seen is specific to osteogenesis only or applicable to the 
maintenance of MSC stemness in general remains to be investigated. In either case, it may be that MSCs in the marrow stroma are often in contact with similar nascent OB matrix and are thus kept in an undifferentiated state. In a traumatic bone injury setting, MSCs would be called forth to migrate from their niche to the site of fracture where they would come into contact with mature bone and its matrix, which would then act to stimulate their osteogenic differentiation via matrix-entrapped growth factors. This model, if proven correct, will strongly suggest that the $\mathrm{OBC}$ matrix and/or its active components may be applied in vitro to develop a means to extend the proliferative potency and therapeutic utility of MSCs by suppressing their default osteogenic differentiation.

\section{Additional files}

Additional file 1: Table S1. Primer sequences of genes analyzed by real-time RT-PCR for osteogenesis. (DOCX $50 \mathrm{~kb}$ )

Additional file 2: Figure S1. Dil labeling does not affect MSC osteogenic gene expression. MSCs were labeled with Dil and cultured in EM or OM for 21 days. Osteocalcin (OC) mRNA expression was measured by real-time RT-PCR and normalized to GAPDH. Unlabeled MSCs were used as controls. Values shown are mean \pm SD from cells isolated from a

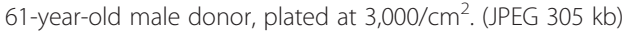

Additional file 3: Figure S2. Morphology of Dil-labeled MSCS in co-culture with unlabeled OBCs. Images of MSCs on culture days 6 and 12 show no obvious morphological differences due to co-culture with OBCs. Shown are unlabeled MSCs in EM; Dil-labeled MSCs mixed with unlabeled MSCs in OM as a control (MSC/MSC*); and Dil-labeled MSCs mixed with unlabeled $\mathrm{OBC}$ in $\mathrm{OM}\left(\mathrm{OBC} / \mathrm{MSC} \mathrm{C}^{*}\right.$ ). MSCs were derived from a 73-year-old male donor, plated at 9,000 cells $/ \mathrm{cm}^{2}$ and cultured in a 1:4 ratio with OBCs induced from the same MSCs for 15 days prior to co-culture. MSC* indicates MSCs labeled with Dil (red). 10× magnification. (JPEG $1025 \mathrm{~kb}$ )

Additional file 4: Figure S3. Effects of OBC co-culture on MSC osteogenic gene expression is variable. mRNA levels of osteogenic genes (OC, Runx2, ALP, and Col I) in MSC control cultures and MSC/OBC co-cultures were measured via real-time RT-PCR, and normalized to GAPDH. Each value was then expressed as a percentage of the maximum level reached for that gene in cells from a given donor within a given experiment. Values shown are the mean \pm SEM from two experiments. No statistically significant differences were observed. (JPEG $238 \mathrm{~kb}$ )

Additional file 5: Figure S4. Minimal effects of OBC-conditioned medium on MSC osteogenic gene expression. mRNA levels of OC, Runx2, ALP, and Col I measured via real-time RT-PCR (normalized to GAPDH) were compared between MSCs in OBC-conditioned OM (CM) versus those in the control aged OM (AOM) cultured for 3, 6 and 12 days. Mean fold changes on each day from three experiments are shown (mean \pm SD). None of the changes in gene expression upon exposure to OBCCM were greater than 1.7 -fold, and none of them were statistically significant. (JPEG $147 \mathrm{~kb}$ )

Additional file 6: Figure S5 Microarray analysis confirms the suppression of osteogenesis by OBC matrices. MSCs from three donors were cultured in $\mathrm{OM}$ on $\mathrm{OBC}$ matrices prepared by water or DOC lysis, and gene expression analyzed by real-time RT-PCR using the SuperArray System. Gene-of -interest CT values were normalized to the average of five housekeeping genes. Shown are those genes that showed mean fold changes > 3-fold when comparing MSCs on matrix to MSCs on plastic in $\mathrm{OM}$ at days 6 and 12. Genes were assigned to graph (A) or (B) based on alphabetical order. Asterisks indicate significance between an experimental condition and the OM plastic control. There was no statistical significance in any differences $>3$-fold between matrix treatments. ${ }^{*}, \mathrm{p}<0.05 ;{ }^{* *}, \mathrm{p}<0.01$. (JPEG $427 \mathrm{~kb}$ )

Additional file 7: Figure S6. Comparison of the matrix effect of human foreskin fibroblasts and osteoblastic cells on osteogenic differentiation of MSCs. HFF and OBC cultures were water-lysed and the resultant matrices used as a substrate for MSCs cultures maintained in osteogenic medium. ALP activity was detected histochemically. Non-MSC seeded HFF and OBC matrices were used as control. The results showed that HFF matrix did not suppress MSC osteogenesis, compared to OBC matrix. OBCs were derived from day-15 osteogenic culture of bone marrow derived MSCS from a 47-year-old female donor. (JPEG $637 \mathrm{~kb}$ )

Additional file 8: Table S2. Protein symbols used for proteomic analysis. (DOCX $122 \mathrm{~kb}$ )

\section{Competing interests}

The authors declare that they have no competing interests.

\section{Authors' contributions}

Study design: CK, LS, JH and RT. Study conduct: CK, JH. Data collection: CK. Data analysis: CK. Data interpretation: CK, LS, JH and RT. Drafting manuscript: CK. Revising manuscript content: CK, LS, JH, and RT. Approving final version of manuscript: $C K, L S, J H$, and RT. All authors take responsibility for the integrity of the data analysis. All authors read and approved the final manuscript.

\section{Acknowledgments}

We sincerely thank Dr. Paul Manner (University of Washington) for providing femoral head tissue samples, and Jim Simone (NIAMS Flow Cytometry Facility), Dr. Lewis Pannell (Proteomics and Mass Spectrometry Laboratory, University of South Alabama), and Roberto Diaz (GE) for countless hours of sample processing and procedural advice. Supported by the $\mathrm{NIH}$ Intramural Research Program (Z01 AR41131) and the Commonwealth of Pennsylvania Department of Health (SAP 4100050913).

\section{Author details}

'Department of Health and Human Services, Cartilage Biology and Orthopaedics Branch, National Institute of Arthritis and Musculoskeletal and Skin Diseases, National Institutes of Health, Bethesda, MD, USA. ${ }^{2}$ Department of Biology, Johns Hopkins University, Baltimore, MD, USA. ${ }^{3}$ Department of Orthopaedic Surgery, Center for Cellular and Molecular Engineering, University of Pittsburgh School of Medicine, 450 Technology Drive, Room 221, Pittsburgh, PA 15219, USA. ${ }^{4}$ Johns Hopkins Medicine, Media Relations and Public Affairs, 901 S. Bond St., Suite 550, Baltimore, MD 21231, USA. ${ }^{5}$ Stryker Orthopedics, 325 Corporate Drive, Mahwah, NJ 07430, USA.

${ }^{6}$ Translational Genomics Research Branch, National Institute for Dental and Craniofacial Research, National Institutes of Health, Bethesda, MD 20892, USA.

Received: 29 December 2014 Revised: 18 January 2015

Accepted: 3 November 2015 Published online: 22 December 2015

\section{References}

1. Bruder SP, Jaiswal N, Haynesworth SE. Growth kinetics, self-renewal, and the osteogenic potential of purified human mesenchymal stem cells during extensive subcultivation and following cryopreservation. J Cell Biochem. 1997:64:278-94

2. Tuan RS, Boland G, Tuli R. Adult mesenchymal stem cells and cell-based tissue engineering. Arthritis Res Ther. 2003;5:32-45.

3. Pittenger MF, Mackay AM, Beck SC, Jaiswal RK, Douglas R, Mosca JD, et al. Multilineage potential of adult human mesenchymal stem cells. Science. 1999;284:143-7.

4. Herzog EL, Chai L, Krause DS. Plasticity of marrow-derived stem cells. Blood. 2003:102:3483-93.

5. Jiang $Y$, Jahagirdar BN, Reinhardt RL, Schwartz RE, Keene CD, Ortiz-Gonzalez $X R$, et al. Pluripotency of mesenchymal stem cells derived from adult marrow. Nature. 2002;418:41-9.

6. Chen X, Armstrong MA, Li G. Mesenchymal stem cells in immunoregulation. Immunol Cell Biol. 2006;84:413-21.

7. Sethe S, Scutt A, Stolzing A. Aging of mesenchymal stem cells. Ageing Res Rev. 2006;5:91-116.

8. Shi $\mathrm{S}$, Gronthos S. Perivascular niche of postnatal mesenchymal stem cells in human bone marrow and dental pulp. J Bone Miner Res. 2003;18:696-704. 
9. Calvi LM, Adams GB, Weibrecht KW, Weber JM, Olson DP, Knight MC, et al. Osteoblastic cells regulate the haematopoietic stem cell niche. Nature. 2003; 425:841-6.

10. Taichman RS, Reilly MJ, Emerson SG. Human osteoblasts support human hematopoietic progenitor cells in vitro bone marrow cultures. Blood. 1996; 87:518-24.

11. Gerstenfeld LC, Cruceta J, Shea CM, Sampath K, Barnes GL, Einhorn TA. Chondrocytes provide morphogenic signals that selectively induce osteogenic differentiation of mesenchymal stem cells. J Bone Miner Res. 2002:17:221-30.

12. Tsai MT, Lin DJ, Huang S, Lin HT, Chang WH. Osteogenic differentiation is synergistically influenced by osteoinductive treatment and direct cell-cell contact between murine osteoblasts and mesenchymal stem cells. Int Orthop. 2012;36:199-205

13. Csaki C, Matis U, Mobasheri A, Shakibaei M. Co-culture of canine mesenchymal stem cells with primary bone-derived osteoblasts promotes osteogenic differentiation. Histochem Cell Biol. 2009;131:251-66.

14. Ye CP, Heng BC, Liu H, Toh WS, Cao T. Culture media conditioned by heat shocked osteoblasts enhances the osteogenesis of bone marrow-derived mesenchymal stromal cells. Cell Biochem Function. 2007;25:267-76.

15. Wang Y, Volloch V, Pindrus M, Blasioli DJ, Chen J, Kaplan DL. Murine osteoblasts regulate mesenchymal stem cells via WNT and cadherin pathways: mechanism depends on cell-cell contact mode. J Tissue Eng Regen Med. 2007;1:39-50.

16. Song L, Tuan RS. Transdifferentiation potential of human mesenchymal stem cells derived from bone marrow. FASEB J. 2004;18:980-2.

17. Xie T, Spradling AC. Decapentaplegic is essential for the maintenance and division of germline stem cells in the Drosophila ovary. Cell. 1998;94:251-60.

18. Bendall SC, Stewart MH, Menendez P, George D, Vijayaragavan K, Werbowetski-Ogilvie T, et al. IGF and FGF cooperatively establish the regulatory stem cell niche of pluripotent human cells in vitro. Nature. 2007; 448:1015-21.

19. Gronthos S, Chen S, Wang CY, Robey PG, Shi S. Telomerase accelerates osteogenesis of bone marrow stromal stem cells by upregulation of CBFA1, osterix, and osteocalcin. J Bone Miner Res. 2003;18:716-22.

20. Urist MR. Bone: formation by autoinduction. Science. 1965;150:893-9.

21. Shi S, Kirk M, Kahn AJ. The role of type I collagen in the regulation of the osteoblast phenotype. J Bone Miner Res. 1996;11:1139-45.

22. Arikawa E, Quellhorst G, Han Y, Pan H, Yang J. RT2 Profiler PCR Arrays: pathway-focused gene expression profiling with qRT-PCR. SABiosciences Technical Article. http://www.sabiosciences.com/manuals/ pcrarraywhitepaper.pdf

23. Mizuno D, Agata H, Furue $H$, Kimura A, Narita Y, Watanabe N, et al. Limited but heterogeneous osteogenic response of human bone marrow mesenchymal stem cells to bone morphogenetic protein-2 and serum. Growth Factors. 2010;28:34-43.

24. Lozito TP, Kolf CM, Tuan RS. Microenvironmental regulation of adult mesenchymal stem cells. In: Rajasekhar VK, Vemuri MC, editors. Regulatory networks in stem cells. Totowa, NJ: Humana/Springer Press; 2009. p. 185-210.

25. Heng BC, Cao T, Stanton LW, Robson P, Olsen B. Strategies for directing the differentiation of stem cells into the osteogenic lineage in vitro. J Bone Miner Res. 2004;19:1379-94.

26. Salasznyk RM, Williams WA, Boskey A, Batorsky A, Plopper GE. Adhesion to vitronectin and collagen I promotes osteogenic differentiation of human mesenchymal stem cells. J Biomed Biotechnol. 2004;2004:24-34.

27. Cool SM, Nurcombe V. Substrate induction of osteogenesis from marrowderived mesenchymal precursors. Stem Cells Dev. 2005;14:632-42.

28. Heckmann L, Fiedler J, Mattes T, Brenner RE. Mesenchymal progenitor cells communicate via alpha and beta integrins with a three-dimensional collagen type I matrix. Cells Tissues Organs. 2006;182:143-54.

29. Urist MR, Mikulski A, Lietze A. Solubilized and insolubilized bone morphogenetic protein. Proc Natl Acad Sci USA. 1979;76:1828-32.

30. Becerra J, Andrades JA, Ertl DC, Sorgente N, Nimni ME. Demineralized bone matrix mediates differentiation of bone marrow stromal cells in vitro: effect of age of cell donor. J Bone Miner Res. 1996;11:1703-14.

31. Dimitriou R, Tsiridis E, Giannoudis PV. Current concepts of molecular aspects of bone healing. Injury. 2005;36:1392-404.

32. Einhorn TA. The cell and molecular biology of fracture healing. Clin Orthop Relat Res. 1998;355(Suppl):7-21.
33. Kirk MD, Kahn AJ. Extracellular matrix synthesized by clonal osteogenic cells is osteoinductive in vivo and in vitro: role of transforming growth factor-beta 1 in osteoblast cell-matrix interaction. J Bone Miner Res. 1995;10:1203-8.

34. Chen XD, Dusevich V, Feng JQ, Manolagas SC, Jilka RL. Extracellular matrix made by bone marrow cells facilitates expansion of marrow-derived mesenchymal progenitor cells and prevents their differentiation into osteoblasts. J Bone Miner Res. 2007;22:1943-56.

35. Lai Y, Sun Y, Skinner CM, Son EL, Lu Z, Tuan RS, et al. Reconstitution of marrow-derived extracellular matrix ex vivo: a robust culture system for expanding large-scale highly functional human mesenchymal stem cells. Stem Cells Dev. 2010;19:1095-107.

36. Volloch V, Olsen BR. Why cellular stress suppresses adipogenesis in skeletal tissue, but is ineffective in adipose tissue: control of mesenchymal cell differentiation via integrin binding sites in extracellular matrices. Matrix Biol. 2013;32:365-71.

37. Reyes M, Lund T, Lenvik T, Aguiar D, Koodie L, Verfaillie CM. Purification and ex vivo expansion of postnatal human marrow mesodermal progenitor cells. Blood. 2001;98:2615-25.

38. King MW, Neff AW, Mescher AL. Proteomics analysis of regenerating amphibian limbs: changes during the onset of regeneration. Int J Dev Biol. 2009;53:955-69.

39. Buhr N, Carapito C, Schaeffer C, Hovasse A, Van Dorsselaer A, Viville S. Proteome analysis of the culture environment supporting undifferentiated mouse embryonic stem and germ cell growth. Electrophoresis. 2007;28: $1615-23$.

40. Hashimoto K, Noshiro M, Ohno S, Kawamoto T, Satakeda H, Akagawa Y, et al. Characterization of a cartilage-derived 66-kDa protein (RGD-CAP/beta ig-h3) that binds to collagen. Biochim Biophys Acta. 1997;1355:303-14.

41. Wagner W, Wein F, Roderburg C, Saffrich R, Faber A, Krause U, et al. Adhesion of hematopoietic progenitor cells to human mesenchymal stem cells as a model for cell-cell interaction. Exp Hematol. 2007;35:314-25.

42. Gan OI, Murdoch B, Larochelle A, Dick JE. Differential maintenance of primitive human SCID-repopulating cells, clonogenic progenitors, and longterm culture-initiating cells after incubation on human bone marrow stromal cells. Blood. 1997:90:641-50.

43. Ohno S, Doi T, Fujimoto K, ljuin C, Tanaka N, Tanimoto K, et al. RGD-CAP (betaig-h3) exerts a negative regulatory function on mineralization in the human periodontal ligament. J Dent Res. 2002;81:822-5.

44. Hadfield KD, Rock CF, Inkson CA, Dallas SL, Sudre L, Wallis GA, et al. HtrA1 inhibits mineral deposition by osteoblasts: requirement for the protease and PDZ domains. J Biol Chem. 2008;283:5928-38.

45. Tiaden AN, Breiden M, Mirsaidi A, Weber FA, Bahrenberg G, Glanz S, et al. Human serine protease HTRA1 positively regulates osteogenesis of human bone marrow-derived mesenchymal stem cells and mineralization of differentiating bone-forming cells through the modulation of extracellular matrix protein. Stem Cells. 2012;30:2271-82.

46. Zacchigna L, Vecchione C, Notte A, Cordenonsi M, Dupont S, Maretto S, et al. Emilin1 links TGF-beta maturation to blood pressure homeostasis. Cell. 2006;124:929-42

47. Antebi B, Zhang Z, Wang Y, Lu Z, Chen XD, Ling J. Stromal-cell-derived extracellular Mmtrix promotes the proliferation and retains the osteogenic differentiation capacity of mesenchymal stem cells on three-dimensional scaffolds. Tissue Eng Part C Methods. 2015:21:171-81.

48. Pei M, He F, Kish VL. Expansion on extracellular matrix deposited by human bone marrow stromal cells facilitates stem cell proliferation and tissuespecific lineage potential. Tissue Eng Part A. 2011;17:3067-76.

49. Lozito TP, Taboas JM, Kuo CK, Tuan RS. Mesenchymal stem cell modification of endothelial matrix regulates their vascular differentiation. J Cell Biochem. 2009:107:706-13

50. Lin H, Yang G, Tan J, Tuan RS. Influence of decellularized matrix derived from human mesenchymal stem cells on their proliferation, migration and multi-lineage differentiation potential. Biomaterials. 2012;33:4480-9.

51. Sun Y, Li W, Lu Z, Chen R, Ling J, Ran Q, et al. Rescuing replication and osteogenesis of aged mesenchymal stem cells by exposure to a young extracellular matrix. FASEB J. 2011;25:1474-85. 